\title{
Estrategia didáctica para la comprensión de dilemas morales con apoyo en las TIC*
}

\section{Didactic strategy for understanding of moral dilemmas with support in ICT}

\author{
María Trinidad Gómez Martínez', Rafael Iván Rodríguez Suárez²
}

Para citar este artícullo: Gómez, M. T.; Rodríguez, R. I.

Recibido: 14-marzo-2018 / Aprobado: 21-septiembre-2018

(2018). Estrategia didáctica para la comprensión de dilemas morales con apoyo en las TIC. Infancias Imágenes, $18(1), 9-20$

\section{Resumen}

El proyecto consistió en diseñar y desarrollar una estrategia didáctica que permitiera integrar las tecnologías de la información y la comunicación en la apropiación de dilemas morales en los niveles básica y media de instituciones educativas de la provincia de Guanentá (departamento de Santander, Colombia). La propuesta buscó responder a las necesidades de construcción de conocimiento en el campo de la educación en competencias ciudadanas. Asimismo, el uso de dilemas morales propició espacios reflexivos que afianzaron la dimensión moral, social, afectiva y cognitiva de los estudiantes. La metodología se basó en el paradigma de la investigación-acción (I-A) en educación, siendo un proyecto de innovación pedagógica. El desarrollo se planteó en tres fases: reflexión; planeación y ejecución de acciones; y evaluación de resultados. La población estuvo conformada por seis núcleos geográficos de la provincia de Guanentá. Los resultados evidenciaron un impacto positivo y transformador en las prácticas educativas de los beneficiarios.

Palabras clave: tecnología de la información, educación ciudadana, desarrollo moral, innovación pedagógica.

\section{Abstract}

The project consisted of designing and developing a didactic strategy that would allow the integration of information and communication technologies in appropriation of moral dilemmas in basic and middle levels of educational institutions in the province of Guanentá (Santander, Colombia). The proposal sought to meet the needs of knowledge-building in the field of education in citizenship skills. Likewise, the use of moral dilemmas led to reflective spaces that strengthened the moral, social, affective and cognitive dimension of students. The methodology was based on the paradigm of action research in education, being a pedagogical innovation project. The development was proposed in three phases: reflection; planning and execution of actions; and evaluation of results. The population consisted of six geographical cores of the province of Guanentá. The results showed a positive and transformative impact on the educational practices of the beneficiaries.

Keywords: information technology, civic education, moral development, teaching method innovations.

* Diseño e implementación de una estrategia didáctica para la apropiación de dilemas morales con apoyo en las tecnologías de la información y la comunicación (TIC) fue un proyecto de investigación, auspiciado por Colciencias y ejecutado por Unisangil, que formó parte del programa Ciudadanía desde el aula: Programa de estrategias y orientaciones didácticas para la educación en competencias ciudadanas en la provincia de Guanentá (Santander, Colombia). El proyecto inició el 1 de septiembre de 2015 y finalizó el 30 de agosto de 2017.

1 Magistra en Desarrollo Rural. Especialista en Pedagogía para el Desarrollo de la Inteligencia. Licenciada en Ciencias Sociales y Económicas. Directora de la Especialización en Pedagogía para el Desarrollo de la Inteligencia, Fundación Universitaria de San Gil (Unisangil). Correo electrónico: mgomez@unisangil.edu.co

2 Magíster en Resolución de Conflictos y Mediación Social. Especialista en Intervención Psicosocial. Psicólogo. Docente, Fundación Universitaria de San Gil (Unisangil).Correo electrónico: rrodriguez@unisangil.edu.co 


\section{Introducción}

Desde una mirada crítica a la realidad actual, podemos entrever la importancia que tiene la formación para la ciudadanía como camino que contribuye al acercamiento a una cultura de paz. El logro de este interés superior debería promoverse desde la transformación de múltiples imaginarios sociales y modos de relación que perpetúan la negación de la legitimidad del otro como interlocutor válido, como sujeto de derechos y deberes y, en suma, como copartícipe de la vida en común.

Esto último nos remite a pensar que la formación de una nueva ciudadanía se constituye en un reto de alto valor para la sociedad emergente, una tarea inaplazable y un compromiso que convoca a diversos actores que configuran el sistema social. Así las cosas, la escuela, como espacio privilegiado de transmisión de la cultura, está Ilamada a liderar estas transformaciones y a instaurarse como plataforma de lanzamiento para el ejercicio de nuevas formas de ciudadanía.

Considerando lo dicho, presentamos aquí la experiencia lograda con el diseño e implementación de una estrategia didáctica para la comprensión de dilemas morales con apoyo en las TIC. Se trata de un proyecto enmarcado en el paradigma de la I-A en educación, que hizo parte del programa Ciudadanía desde el aula ${ }^{3}$, el cual buscó desarrollar estrategias y orientaciones didácticas para educar en competencias ciudadanas en establecimientos educativos de la provincia de Guanentá (Santander, Colombia). A lo largo de este texto, veremos que el reto de la formación ciudadana permite aprovechar la escuela como agente dinamizador de mejores espacios de convivencia y, con ello, optimizar los múltiples recursos que dan forma al acto pedagógico.

\section{Panorama general de la experiencia}

La reflexión sobre los procesos de formación para la ciudadanía y, en específico, para el desarrollo de competencias ciudadanas, encuentra significado en la medida en que se busca trascender en la educación de personas que aportan en la construcción

3 Toda la información y los recursos dispuestos por el programa Ciudadanía desde el aula pueden ser consultados en la página web: http:// www.ciudadaniadesdeelaula.com/ de una sociedad más participativa, democrática y orientada por el respeto de los derechos humanos. El caso particular de la metodología y las didácticas más apropiadas para la mediación, potenciación y apropiación de este tipo de competencias se configura como una inquietud que involucra a diversos actores educativos en la tarea de aportar estrategias innovadoras acompasadas con las dinámicas que hoy en día plantea la realidad.

En el marco de esta experiencia, conviene tener presente que las zonas rurales y urbanas del departamento de Santander son, como muchas otras regiones de Colombia, terreno prolífico para la ocurencia de diversos fenómenos psicosociales que afectan de manera negativa el equilibrio y el bienestar social. En una investigación desarrollada por Barragán y Arias (2014) se encontró que entre tales fenómenos se destacan: la violencia intrafamiliar, la desestructuración del núcleo familiar, la exclusión social, entre otras. No obstante, es preocupante también la escasa reflexión de los estudiantes sobre lo que la condición de ciudadano exige y las maneras como se resuelven las encrucijadas morales cotidianas, factores que son clave en la intención de promover procesos de desarrollo humano y social integrales.

Esta experiencia investigativa (Barragán y Arias, 2014) logró el diseño y validación de dilemas morales adecuados para estudiantes de básica secundaria en entornos rurales; además, permitió deducir que la población infantojuvenil encontraría, al desarrollar dilemas morales en la escuela, un espacio para evolucionar en sus competencias cognitivas, emocionales y comunicativas (elementos de sostén de las competencias ciudadanas). Sin embargo, se advierten algunos riesgos didácticos como: caer en el terreno de la retórica, no lograr escenarios auténticos de discusión y debate en el aula, convertir los dilemas en textos de poca significación para el estudiante, etc. Esto podría ocasionar que las bondades de los dilemas morales queden atrapadas en filtros afectivos de los estudiantes.

Allí anida el problema que se abordó en este proyecto: la necesidad de una metodología que motive a los estudiantes para abordar los retos propios de los dilemas morales (análisis, reflexión, discusión, pensamiento crítico, etc.). Por eso, se 
consideró que al aprovechar la disposición natural de los estudiantes de básica secundaria y media hacia la interacción con las TIC se conseguiría también una disposición hacia el análisis y la reflexión de dilemas morales.

En síntesis, al establecer una relación entre el desarrollo de dilemas morales en el contexto escolar y las TIC se esperaba aportar una innovación pedagógica que contribuya al desarrollo de competencias ciudadanas de la población mencionada. El interrogante principal que resultó fue: ¿cuál sería una estrategia didáctica para la apropiación de dilemas morales con apoyo en las TIC en básica secundaria y media de la provincia de Guanentá?

\section{Competencias ciudadanas: un enfoque posible}

Profundizando un poco más en lo precedente, el reto de propiciar nuevas formas de ciudadanía está refrendado en el sistema escolar colombiano con la adopción del modelo de competencias ciudadanas. El desarrollo de estas competencias es una de las rutas sugeridas para la promoción de nuevas formas de representar la realidad y de actuar en el mundo relacional de los niños, niñas y adolescentes vinculados en la escuela. En palabras de Cháux:

La propuesta de Competencias Ciudadanas se enfoca justamente en aquello que se requiere para la acción ciudadana. Las competencias ciudadanas se pueden definir como aquellas capacidades cognitivas, emocionales y comunicativas que, integradas entre sí y relacionadas con conocimientos y actitudes, hacen posible que el ciudadano actúe de manera constructiva en la sociedad. (2012, p. 66)

Existen, en efecto, numerosas razones que nos hacen ver que este enfoque es una apuesta directa para la formación de nuevos ciudadanos. La escuela, como ente socializador, propicia la convergencia de múltiples procesos cognitivos, afectivos y sociales que, en conjunto, inciden en los modos de representar la realidad y actuar en ella. Esto último desde la perspectiva de los niños, niñas y adolescentes que se reúnen en los escenarios escolares. Como lo expone Pereira:
Nuestros jóvenes conviven con la violencia y es nuestra responsabilidad acompañarlos en el proceso de aprendizaje necesario para que lo que piensan (habilidades cognitivas), lo que sienten (desarrollo moral y habilidades emocionales) y lo que hacen (habilidades sociales) en relación a ella, les haga competentes como ciudadanos pacíficos. (2011, p. 74)

No podemos dejar de señalar que la función de la escuela es mayúscula. Los dispositivos curriculares, manifiestos y encubiertos, se instauran como reproductores y productores de la cultura. Por eso, las instituciones que se comprometen a hacer vivencial el enfoque de competencias ciudadanas configuran escenarios libertarios que, como indica Nussbaum "liberan la mente de la esclavitud de los hábitos y la costumbre, formando personas que puedan actuar con sensibilidad y agudeza mental como ciudadanos del mundo" (2005, p. 16). Es, en suma, un enfoque posible que adelanta pasos en la tarea de construir nuevas formas de ciudadanía.

\section{Acerca del acto pedagógico: personas y recursos didácticos}

En función de lo expuesto, hay que decir que la misión de formar para la ciudadanía no es un propósito que se ubique por fuera del acto pedagógico. Por el contrario, requiere de maestros que lideren la mediación, estudiantes dispuestos a transformar su experiencia y recursos didácticos que actúen como potenciadores para el desarrollo de las competencias. Muy próximos a lo dicho, lo amplía Filloux en estos términos:

El "campo" pedagógico se convierte en un objeto epistémico de investigación, a nivel de las prácticas, de los discursos que se producen en su interior y en esa parte externa que son las doctrinas o teorías denominadas "pedagógicas". Pero sin olvidar que el que es llamado pedagogo (el docente, el maestro) y el que es Ilamado alumno (el aprendiz) son los socios, los sujetos que constituyen en su acción lo "pedagógico" en el seno del sistema institucional que funda el espacio escolar. (2001, pp. 10 y 11) 
Tenemos en cuenta que los elementos que aquí se involucran (maestros, estudiantes y recursos didácticos) deben ser entendidos desde la dimensión propia de las intencionalidades encaminadas al desarrollo de competencias ciudadanas. En ese panorama, el repertorio de actuaciones del maestro se ubica como un ingrediente principal de lo que sería una estrategia didáctica efectiva. Y, como sostiene Rosas:

La tarea del educador, encuentra su fundamento en su deseo de que el educando recorra el camino de interacciones que lo llevará a constituirse como un ser humano en sentido propio. Para lograr este objetivo, su responsabilidad básica es interactuar constantemente con el educando de acuerdo al emocionar que desea que éste desarrolle de manera permanente, emocionar que no es otro que el amor (como sabemos, entendido como la constante aceptación del otro como legítimo otro). (2008, p. 101)

Dicho esto, se hace evidente que el papel que desempeña el maestro es determinante en el logro 12 de aquello que se propone el acto educativo. El caso particular del diseño que aquí se expone requiere, como expresa Gardner tener presente que "los educadores pueden facilitar la consecución de la mente ética destacando las otras acepciones de la palabra «bueno». Los estudiantes deben entender por qué aprenden lo que aprenden y cómo se puede aplicar este conocimiento de una forma positiva" (2005, p. 59). Y es esa función de facilitación la que ubica el propósito superior de la mediación en el terreno real de las manifestaciones de ciudadanía.

En paralelo, la labor del maestro se ve afianzada cuando existen estrategias didácticas que favorecen la apropiación de conocimientos y la atribución de significados conectados con la realidad. Esto puede ser dimensionado con mayor claridad en el terreno de lo práctico, cuando se entiende la estrategia didáctica como un sistema de elementos que se articulan para favorecer el desarrollo de competencias. Y, como muestran Coll et al., se alcanza una visión de la estrategia en estos términos:

Conjunto ordenado de actividades, estructuradas y articuladas para la consecución de un objetivo educativo en relación a un contenido concreto. En esta unidad se tiene en cuenta los contenidos de aprendizaje y el correspondiente objetivo educativo, el papel que se otorga al profesor y al alumno, los materiales curriculares y el uso que se les ha de dar, y los medios, momentos y criterios para la evaluación. (2007, p. 147)

Como podemos ver, la estrategia didáctica convoca personas, recursos, intencionalidades y otros factores que en consonancia disponen el terreno para el desarrollo de nuevas competencias. Uno de estos elementos, central en el proyecto aquí descrito, son los dilemas morales como recurso didáctico.

La metodología de discusión de dilemas morales en el aula endosa al docente roles específicos, pues debe ser él quien presente a los estudiantes el dilema (usando un texto escrito leyéndolo en voz alta) y luego concierta las reglas de interlocución y vela por su cumplimiento. No obstante, quizás el mayor reto del docente es no tomar partido, no influir con sus posiciones en el debate y en las decisiones de los estudiantes, convencido de que la finalidad no es llegar a la opción correcta sino desarrollar en los estudiantes importantes habilidades para la vida. Entre estas se incluyen, según Mantilla y Chaín: "toma de decisiones, pensamiento crítiCo, comunicación asertiva, solución de problemas y conflictos y empatía" (2010, p. 48).

Hacemos resaltar, entonces, que el dilema moral como recurso didáctico tiene un lugar en la tradición investigativa en diversos campos disciplinares. Los trabajos de Lind (2005) y Chaux (2012) son muestra de ese trasfondo que, explicado por Bermúdez y Jaramillo, implica lo siguiente:

Un dilema es una breve historia sobre un personaje que enfrenta una situación difícil y tiene que tomar una decisión sobre la mejor acción a seguir. Aquella que tome involucra aspectos importantes de su vida, pero también puede afectar a otras personas. Por esta razón el personaje debe tomar una decisión que sea buena, correcta o justa consigo mismo y con los demás que se verán afectados por ella, de allí que deba enfrentarse a una situación moral. (2000, p. 35)

Es conveniente complejizar e interrogarnos sobre el alcance de este recurso porque, como vemos, 
van saliendo a la luz conexiones entre el propósito que orienta al enfoque de competencias ciudadanas y la incidencia del recurso didáctico en las dimensiones de desarrollo moral, cognitivo, afectivo y social de los estudiantes. El dilema moral estimula la imaginación narrativa y, como indica Nussbaum, esto significa "la capacidad de pensar cómo sería estar en el lugar de otra persona, ser un lector inteligente de la historia de esa persona, y comprender las emociones, deseos y anhelos que alguien así pudiera experimentar" (2005, p. 19).

Debemos considerar con atención, tal como propone Gómez-Heras, que "el contexto de la reflexión moral da por supuesto el respeto hacia las convicciones ajenas, la tolerancia mutua y la libertad. Se excluyen, por el contrario, el dogmatismo ideológico y el totalitarismo sociopolítico como actitudes inconciliables con el pluralismo" (2004, p. 27). Esto, como anticipamos, es consecuente con los propósitos de la formación ciudadana y ubica al recurso de dilemas morales como una herramienta con alto potencial de aprovechamiento en el ámbito escolar.

Ahora bien, el recurso en sí mismo no lo vemos como un fin en el acto pedagógico sino como un medio para alcanzar propósitos superiores. Por eso, el enfoque participativo que aquí se asumió cuidó el carácter significativo del dilema en relación con la realidad contextual de los participantes porque, como indica Camps haciendo referencia a los dilemas éticos o dilemas morales, es importante tener presente que:

Todos tenemos intereses particulares y valoramos lo que nos encontramos a partir de ellos y de las pasiones que suscitan. No somos seres abstractos que razonan fuera de contexto. En el mundo real, la narración de los hechos determina la forma de evaluarlos. (2011, p. 263)

Gómez-Heras expone en síntesis lo siguiente: "La coexistencia de sistemas culturales y la inevitable colisión de valores urgen a poner en práctica métodos y procedimientos (el diálogo o el razonamiento discursivo), que a partir de la pluralidad permitan recuperar espacios de unidad en el consenso" (2004, p. 27). El dispositivo de dilemas morales, entonces, se muestra como un recurso que apunta a promover encuentros dialógicos razonados. Sin embargo, el elemento diferenciador que aquí incluimos fue la integración de las TIC para optimizar y potenciar su desempeño.

\section{En carácter innovador de la experiencia}

El término innovación sirve como descriptor útil para entender características asociadas a lo nuevo, lo inesperado, aquello que aún debe ser explorado más a fondo para agotar su conocimiento. En el marco de este proyecto, pensamos la innovación pedagógica en función del dispositivo de dilemas morales y, con ello, de la acción del docente para usarlo como recurso didáctico en la mediación. De modo particular, la integración de las Tecnologías de la Información y las Comunicaciones (TIC) sirven a ese propósito y estimulan un clima creativo e interactivo para la dinamización grupal.

Bauman y Donskis advierten que "formamos parte del nuevo relato humano, que en épocas anteriores adoptó la forma de épica, saga o novela y ahora se exhibe en pantallas de televisión y monitores de ordenador" (2015, p. 15). Es fácil, entonces, observar que en la actualidad los productos comunicativos se han digitalizado y los avances provistos por la ciencia y la tecnología configuran nuevas modalidades de acceso a la información y, con ello, nuevas formas de relación e interacción entre los seres humanos. Más aún, la población infantojuvenil exhibe un marcado interés por el uso de estos recursos y es desde esa evidencia que las estrategias pedagógicas pueden incorporar múltiples herramientas para favorecer los procesos de mediación, en diversas áreas, con los estudiantes. En esa línea, contribuye Benavides al decir que:

El uso de la tecnología parece no necesitar reflexión, sino acción en el mundo de la experiencia de la vida diaria, es decir de aplicación en el trabajo. Es mucho más instrumental la relación con la tecnología toda vez que se enfatiza más sobre el dispositivo que sobre el sentido. Sin embargo, el uso de la tecnología de la información en educación, debe ser un campo de reflexión pedagógica. (2005, p. 65) 
En este sentido vemos que la metodología de dilemas morales puede resultar enriquecida con la integración de las TIC en diferentes momentos de la secuencia didáctica y así optimizarse como una herramienta que aporta, desde su efecto en el razonamiento moral, al desarrollo de competencias ciudadanas.

\section{Breviario metodológico de la investigación}

El proyecto tuvo una orientación epistemológica enmarcada en los principios de la I-A en educación. La premisa básica que se asumió desde este marco es que la investigación en educación se hace en el contexto práctico del acto educativo, es decir, es sobre la praxis colectiva que se construye conocimiento que favorezca la transformación de las prácticas pedagógicas. En esa misma línea, Restrepo plantea que la I-A en el campo educativo "requiere la implementación de fases secuenciales con el fin de transformar la práctica y buscar mejorarla en la acción" (2003, p. 8). Estas fases son: la reflexión sobre un área problemática, la planeación y ejecución de acciones alternativas para mejorar la situación problemática y la evaluación de resultados con el fin de emprender un nuevo ciclo de estas fases. Más adelante se hará explícito el ajuste de estos postulados al diseño metodológico del proyecto.

Podemos definir este proyecto como una propuesta de innovación pedagógica, desde la cual se buscó introducir prácticas transformadoras para aportar en el mejoramiento de un sistema educativo en funcionamiento. La propuesta se identificó por su aporte a la innovación pedagógica mediante la generación y aplicación de una estrategia didáctica y el uso de TIC en los contextos escolares.
La población seleccionada para el desarrollo de este proyecto estuvo integrada por instituciones que representan seis núcleos geográficos de la provincia de Guanentá (departamento de Santander, Colombia) con niveles de básica secundaria y media. Específicamente se trabajó con las instituciones públicas urbanas, privadas urbanas y públicas rurales. Los núcleos geográficos estuvieron dispuestos de la siguiente manera:

La selección de los participantes se hizo de acuerdo con los lineamientos de muestra por criterio o fines especiales. Las muestras por fines especiales son muestras por conveniencia en las que, como refiere Corbetta "las unidades de la muestra no se eligen usando procedimientos probabilísticos, sino en función de algunas de sus características" (2010, p. 114). Se realizó una convocatoria para las instituciones educativas y se seleccionaron cuatro docentes de cada núcleo geográfico para un total de 24 participantes. El procedimiento que orientó el desarrollo de la investigación se detalla en la siguiente figura:

Como podemos ver, el proceso de investigación se desarrolló en tres fases centrales distribuidas en los 24 meses de duración del proyecto. En primer lugar, desarrollamos una fase de reflexión sobre el área problemática. En este momento inicial se logró establecer un diagnóstico participativo con los maestros vinculados, con el fin de tener una aproximación directa a su realidad contextual y asegurar la pertinencia de los recursos dispuestos para abordar el problema de investigación. Este punto de partida responde a lo expuesto por Tonda, para quien "toda tarea instructiva o pedagógica se justifica y concreta en una realidad institucional, académica y social" (2001, p. 325). Asimismo, se validaron, mediante validación triangular, los criterios estimados

Tabla 1. Núcleos geográficos

\begin{tabular}{|c|c|c|c|c|c|}
\hline Núcleo 1 & Núcleo 2 & Núcleo 3 & Núcleo 4 & Núcleo 5 & Núcleo 6 \\
\hline $\begin{array}{l}\text { Ocamonte } \\
\text { Charalá } \\
\text { Encino } \\
\text { Coromoro }\end{array}$ & $\begin{array}{l}\text { Jordan Sube } \\
\text { Villanueva } \\
\text { Barichara }\end{array}$ & \begin{tabular}{|l} 
Cabrera \\
Pinchote \\
Valle de San José \\
Páramo
\end{tabular} & $\begin{array}{l}\text { Aratoca } \\
\text { Curití }\end{array}$ & $\begin{array}{l}\text { Mogotes } \\
\text { Onzaga } \\
\text { San Joaquín }\end{array}$ & San Gil \\
\hline
\end{tabular}

Fuente: elaboración propia. 


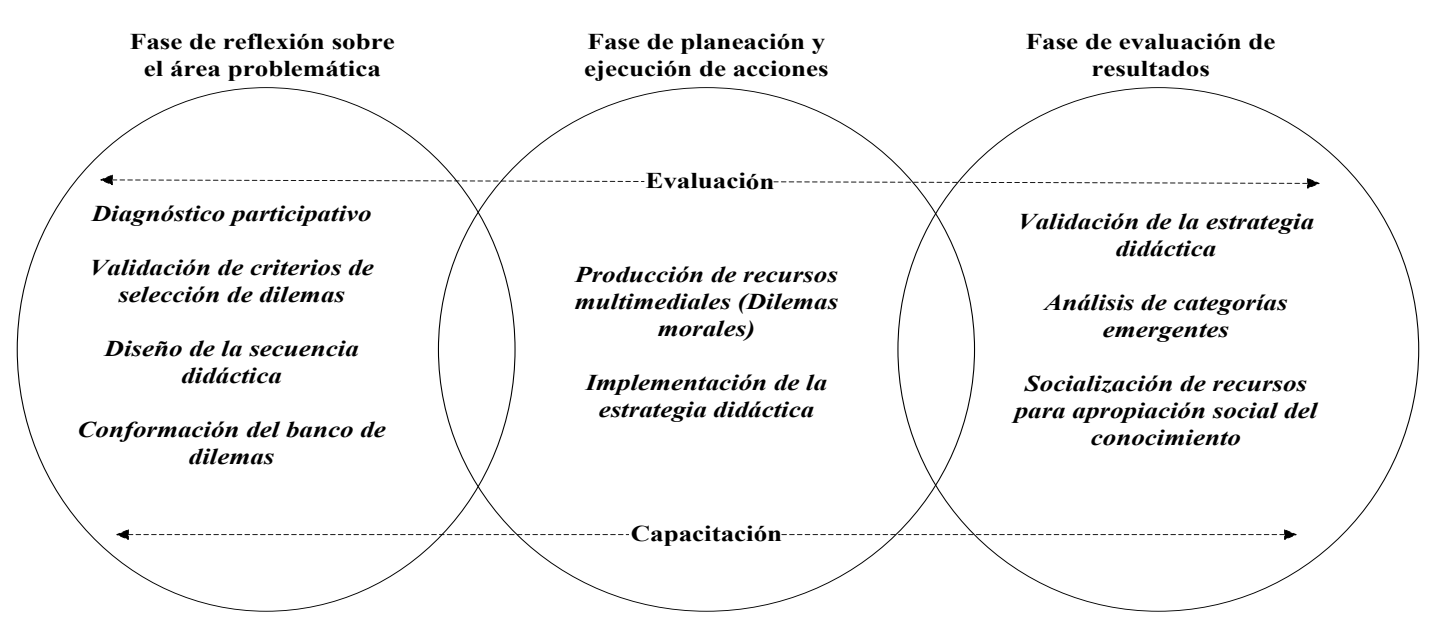

Figura 1. Procedimiento de investigación.

Fuente: elaboración propia.

para seleccionar los dilemas morales que serían insumo para el trabajo posterior y, a partir de estos, se conformó el banco de dilemas morales, un repositorio de textos dilemáticos ajustados a criterio con los que se trabajó en la fase siguiente. A su vez, y desde la misma metodología participativa, se construyó el modelo de secuencia didáctica, aprovechando el saber pedagógico de los docentes y atendiendo a las características de la población vinculada a sus instituciones.

En la fase de planeación y ejecución de acciones logramos formalizar el acceso al campo. Es decir, los maestros participantes iniciaron la implementación de la estrategia didáctica con los grupos de estudiantes seleccionados en sus instituciones. Esta implementación estuvo orientada por el desarroIlo de la secuencia didáctica, haciendo uso de los dilemas morales como recurso y con el elemento diferenciador de la inclusión de TIC en diferentes momentos de la secuencia. En paralelo, se hizo la producción de los recursos multimediales (conjunto de 12 dilemas morales en formato digital), proceso en el cual estuvieron vinculados los maestros de manera permanente.

Una vez finalizada esta fase, llegamos al momento de evaluar los resultados. Desarrollamos el proceso de validación de la estrategia didáctica, valorando los componentes funcionales de la misma y los desempeños percibidos por los maestros en sus estudiantes. Este proceso dio paso a un análisis categorial exhaustivo, con el ánimo de sistematizar los desarrollos alcanzados y así generar un aporte al saber pedagógico que sea susceptible de réplica por parte de otros maestros y otras instituciones del ámbito regional y nacional. Como parte de la estrategia de socialización de resultados y apropiación social del conocimiento, participamos en la producción y difusión de la colección de cartillas y videos de orientaciones didácticas del programa Ciudadanía desde el aula.

En lo fundamental, notamos que este recorrido metodológico se acoge a los principios de la I-A, pues fue un proceso mediado de manera transversal por espacios de capacitación para promover el desarrollo de diversas competencias en los maestros, así como momentos de evaluación periódicos para determinar los hallazgos que iban surgiendo y lograr el afinamiento progresivo de la estrategia didáctica. Los encuentros provinciales, encuentros locales, encuentros por núcleo, paneles temáticos y visitas de campo fueron espacios participativos que durante todo el proceso se dispusieron para asegurar el ejercicio de construcción colectiva de saber pedagógico.

\section{Resultados y análisis de la experiencia} Considerando que el problema de investigación buscaba generar una estrategia didáctica para la apropiación de dilemas morales con apoyo en las TIC, podemos decir que el camino aquí transitado 
permitió construir, desde una modalidad participativa, un modelo integrado, con componentes definidos, viable y pertinente para la implementación en el aula que se puede entender mejor con este modelo categorial:

Situados en este modelo, podemos decir que la estrategia didáctica que resultó del proceso de investigación está integrada por tres componentes centrales: la secuencia didáctica, el dispositivo de dilemas morales y las TIC. Estos tres elementos convergen y se articulan en la configuración de una estrategia con intencionalidades dirigidas al desarrollo de competencias ciudadanas y a las resultantes manifestaciones de ciudadanía.

Observemos, en principio, que la estrategia didáctica está soportada en una secuencia didáctica que dosifica y dinamiza los distintos momentos de la mediación. Esta lógica interna propone una superación de modelos instruccionales (sujeto pasivo-receptor) y privilegia lo significativo del aprendizaje, logrando así vitalizar procesos cognitivos, nández y Guárate delimitan los aspectos que definen a una estrategia didáctica así:

Es el conjunto de acciones y procedimientos, mediante el empleo de métodos, técnicas, medios y recursos que el docente emplea para planificar, aplicar y evaluar de forma intencional, con el propósito de lograr eficazmente el proceso educativo en una situación de enseñanza-aprendizaje específica, según sea el modelo pedagógico y/o andragógico por: contenidos, objetivos y/o competencias para las cuales las elabora y desarrolla. $(2017$, p. 30)

Asimismo, Gowin ve una relación tríadica entre profesor, materiales educativos y aprendiz (1981, p. 45). Para él, un episodio de enseñanza-aprendizaje se caracteriza por compartir significados entre alumno y profesor con respecto a conocimientos "vehiculados" por los materiales educativos del currículum. Usando materiales educativos del currículum, alumno y profesor buscan congruencia de significado. A partir de lo precedente y situados en la experiencia de investigación aquí descrita, la secuencia desarroIlada se muestra en la figura siguiente:

La secuencia resultante, producto de la propuesta, revisión y afinamiento del equipo de investigación, parte del momento de presentación

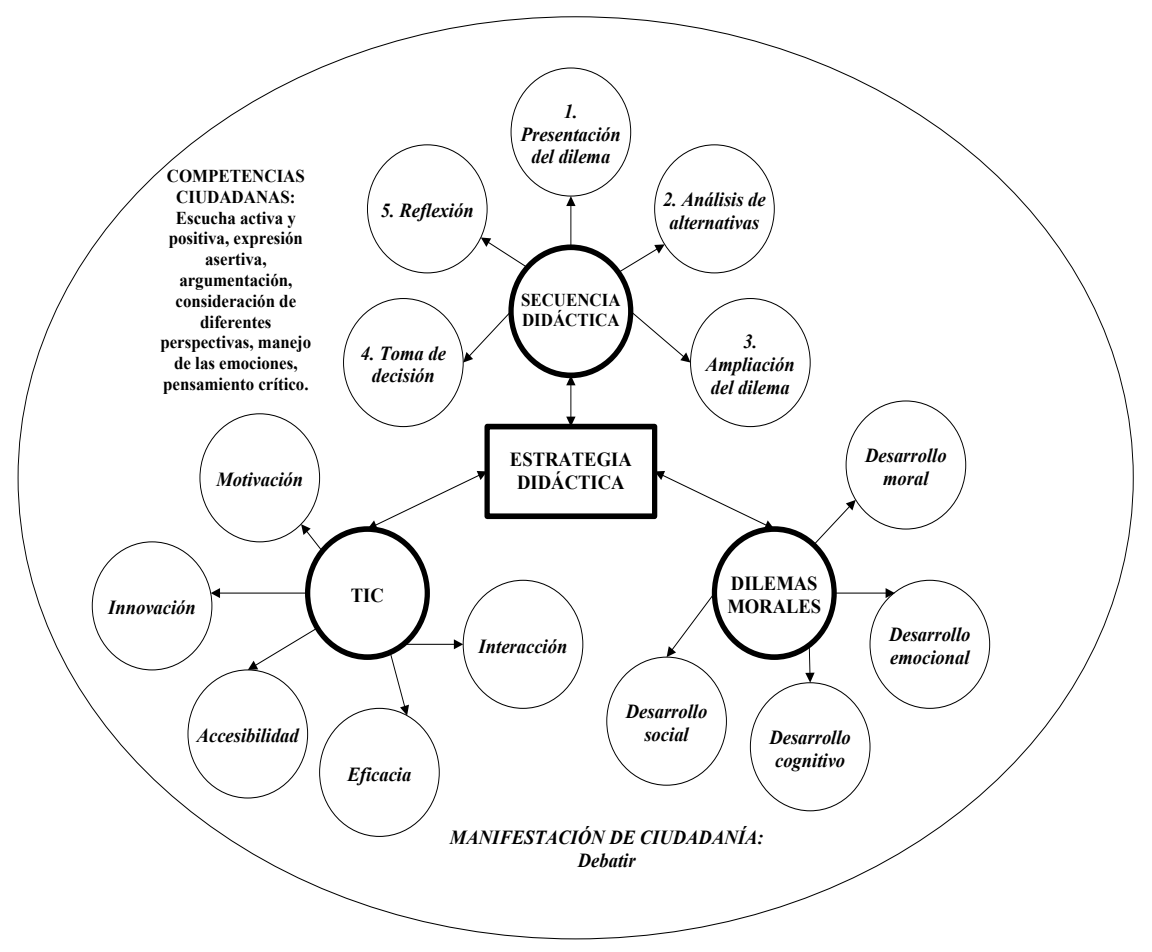

Figura 2. Componentes de la estrategia didáctica.

Fuente: elaboración propia. 


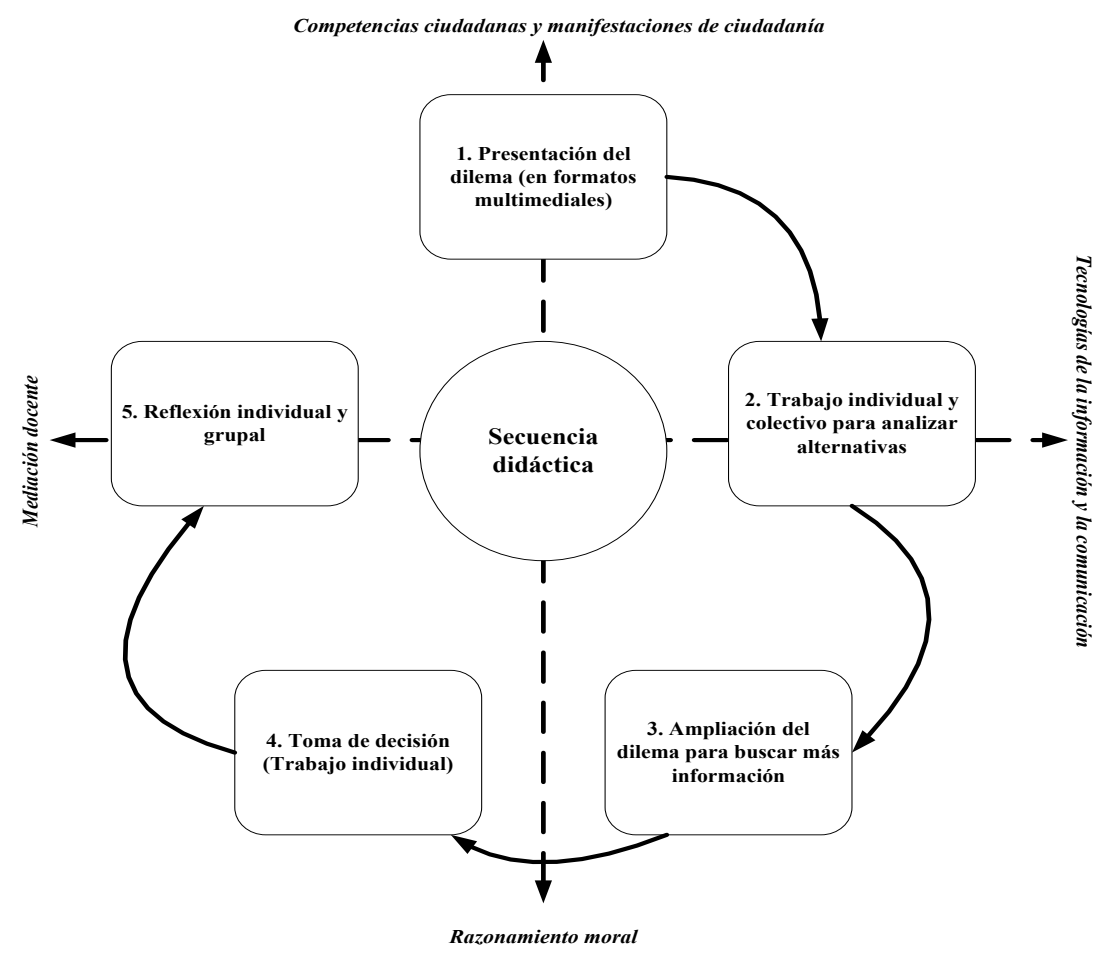

Figura 3. Secuencia didáctica.

Fuente: elaboración propia.

del dilema (en formatos multimedia) para dar paso a una serie de momentos en los que se catalizan procesos de diverso orden: cognitivos, afectivos, morales y sociales. Más allá de lo procedimental, lo que se destacó de la secuencia, según esta experiencia, fue el papel del maestro mediador que logra provocar espacios de construcción colectiva de conocimiento en los que el razonamiento moral se escenifica en el debate y la interlocución entre pares marca el ritmo de los cuestionamientos morales y la toma de decisiones ante las disyuntivas dilemáticas. Sobre esto, Gervilla explica que:

Tras provocar el "conflicto cognitivo" el alumno asimila los nuevos aprendizajes: acomoda y reorganiza sus esquemas mentales para, por último, adaptarse a la nueva situación. Para que esto suceda es fundamental que el profesor de Educación Infantil: 1. Prepare un ambiente que favorezca la predisposición activa del alumno para el aprendizaje (Actitud favorable). 2. Proporcione materiales potencialmente significativos que reúnan los requisitos siguientes: - Presentación adecuada. - Secuenciación correcta.
- Adaptados a sus necesidades e intereses. (2006, p. 26)

Situados en el terreno de la secuencia didáctica, debemos sumar un segundo componente que da forma a la estrategia desarrollada: la inclusión de las TIC. Este elemento de innovación no fue un detalle accesorio, por el contrario, se constituyó en un factor de incidencia pedagógica para el desarrollo de competencias al entender su efecto en la construcción de representaciones cognitivas y su incidencia en la liberación de filtros afectivos y motivacionales por parte de los estudiantes. De manera similar se expresan Caballero, Romero, Barroso y Román, para quienes "la realización de un multimedia, generalmente, suele partir de una idea o necesidad en el aula, o fuera de ella, que nos mueve a generar un material que apoye o solucione la deficiencia que detectamos en el proceso de enseñanza-aprendizaje" (2007, p. 100).

Las TIC, entonces, fueron un medio que se insertaron para optimizar el desempeño y significancia de lo requerido con el dispositivo de dilemas 
morales en distintos momentos de la secuencia didáctica. Verbigracia, el momento 1 (presentación del dilema) le apostó a la inclusión de nuevos formatos (video-animación) para estimular la motivación ante la información aferente y su conexión con situaciones propias de la realidad contextual. Asimismo, los demás momentos de la secuencia didáctica permitieron tomar como apoyo los recursos TIC para su ejecución.

Formatos variados, como los que ofrecen las redes sociales con interacciones sincrónicas y asincrónicas, programas radiales emitidos por la Red Cooperativa de Medios de Comunicación Comunitarios de Santander (Resander) —aliado estratégico del proyecto-, entre otros usos de recursos tecnológicos fueron utilizados para permear la estrategia del componente multimedia.

En sentido general, consideramos que este componente de la estrategia está ligado a categorías emergentes como la motivación que propicia en los estudiantes, el carácter innovador que suscita, 18 las ventajas que ofrece para dinamizar las interacciones grupales, su eficacia como medio para intercambiar, ampliar contenidos en la comunicación y la accesibilidad que, aunque con algunas limitantes en ciertas zonas rurales (infraestructura y conectividad insuficiente para servicios de internet), va progresivamente aumentando en el territorio departamental y nacional.

Estos dos componentes de la estrategia (secuencia didáctica y TIC) se ven consolidados con el recurso didáctico escogido: los dilemas morales. Debemos decir que este dispositivo actuó como eje articulador de la estrategia, tanto en los aspectos metodológicos como en lo concerniente a su efecto en el desarrollo de competencias ciudadanas. Los dilemas morales están, en sí mismos, intencionalmente diseñados para provocar el razonamiento moral, movilizan estructuras cognitivas, pero su uso metodológico trasciende el efecto alcanzando las dimensiones afectiva, moral, cognitiva y social de los estudiantes.

Los dilemas morales se concibieron como un elemento potenciador del desarrollo en diversas áreas de las que conforman la unidad biopsicosocial del ser humano, no se utilizaron como un recurso anexo a la estrategia. Se cuidó la significancia de sus contenidos en relación con las particularidades de la realidad en la que se configura la experiencia vital de los estudiantes de la provincia, aunque muchas de esas circunstancias son susceptibles de generalización en otros contextos.

\section{La estrategia didáctica y el desarrollo de competencias ciudadanas}

Resulta difícil alcanzar una cabal comprensión de la estrategia didáctica que aquí se presentó si no la valoramos desde su efecto en el desarrollo de competencias ciudadanas. El vector que une a la estrategia didáctica, las competencias ciudadanas y la formación para la ciudadanía fue orientador para abordar el problema de investigación. Desde esta perspectiva, y como explican Ausbel, Novak y Hanesian "la adquisición de significado exige invariablemente la traducción del mismo dentro de un marco de referencia personal y su reconciliación con los conceptos y posiciones establecidos" (1976, p. 456). Por ello, se espera que el impacto resultante con esta innovación pedagógica sea un aporte más a la construcción una nueva forma de ser ciudadanos.

Confirmando esta apreciación, el proceso de validación de la estrategia valoró su efecto como favorable para el desarrollo de competencias ciudadanas como las siguientes: escucha activa y positiva, expresión asertiva, argumentación, consideración de diferentes perspectivas, manejo de las emociones y pensamiento crítico. A su vez, el análisis realizado indicó que debatir fue la manifestación de ciudadanía que más notoriedad tuvo.

Esta relación entre competencias ciudadanas y manifestaciones ciudadanía reitera que el enfoque propuesto no es retórico o limitado al alcance teórico, sino que una competencia trasciende al plano vivencial, se manifiesta en la experiencia de quienes la han desarrollado. Y esto, en el terreno de la convivencia y la construcción de ciudadanía, reitera el cumplimiento del objeto misional que sostiene a la estrategia. Señala Zambrano, en relación con lo dicho que:

Si bien es cierto que la escuela no es el único lugar donde los sujetos aprenden las bases de la socialidad; pues al igual lo pueden hacer en el tejido 
asociativo, el sistema de salud, el conjunto de servicios públicos y en las empresas, la escuela sigue representando el único lugar donde reflexionar las contradicciones de todo orden. $(2015$, p. 26)

\section{Adenda de la investigación y conclusiones}

Quisiéramos recapitular aquí algunos fundamentos y hallazgos que se destacaron en el proceso de investigación. Como se ha visto, el proceso tuvo un claro sentido dialéctico y participativo, en el cual la intención de construir conocimiento fue una apuesta por generar transformaciones a través de la innovación pedagógica. De modo que asumir este paradigma orientador permitió rescatar la experiencia de los maestros vinculados al proyecto, haciendo acopio de su saber pedagógico y de su papel como dinamizadores en las comunidades educativas en las que ejercen su labor.

Los escenarios escolares son espacios de participación social en donde convergen diversos actores de la vida comunitaria. Por esto, la integración de los maestros al equipo de investigación evitó ubicarlos como agentes externos y los empoderó como agentes internos, productores de conocimiento, capaces de proponer e implementar cambios en un sistema con intenciones fundamentadas y direccionadas, en este caso, al desarrollo de competencias ciudadanas.

Como se ha mostrado a lo largo de este proyecto, los dilemas morales, el maestro mediador y la estrategia didáctica se conjugan como una fórmula que, lejos de ser infalible, contribuye al proceso de la educación ciudadana. El valor del dispositivo de dilemas morales reside en la posibilidad de reconocer y anticipar el efecto que pueden tener los actos propios en la vida de los demás, proponer una reflexión ética que pone de manifiesto el valor de lo humano como principio superior en la vida en sociedad $y$, a partir de esa premisa, vincular situaciones concretas de la realidad contextual.

Como puede deducirse, la estrategia didáctica le permite al maestro actuar con un plan acorde al recurso específico de los dilemas morales con los que se pretende el desarrollo de juicio moral en los estudiantes. Hay que tener presente que el proceso tuvo un claro sentido dialéctico y participativo, en el cual la intención de construir conocimiento fue una apuesta por generar transformaciones a través de la innovación pedagógica. De modo que asumir este paradigma orientador, permitió rescatar la experiencia de los maestros vinculados al proyecto, haciendo acopio de su saber pedagógico y de su papel como dinamizadores en las comunidades educativas en donde ejercen su labor. Precisamente, esto se relaciona con lo que sostienen Bautista, Borges y Foré cuando afirman que:

También deberíamos considerar que el perfil de nuestros estudiantes está cambiando y cada vez estará más próximo a un perfil de persona saturada de estímulos informativos (la mayoría de naturaleza digital o electrónica). Eso sí, cada vez nos encontraremos con personas poco a poco adaptadas a la interacción telemática y a guiar su propio aprendizaje de una forma algo más autónoma. (2006, p. 90)

Pero retornemos a nuestro punto de partida: la realidad actual exige un ejercicio de la acción ciudadana liderada por sujetos participativos y comprometidos con el bien común. Este nuevo ciudadano se construye desde los espacios de socialización que configuran su desarrollo; así, la escuela se ubica como un espacio privilegiado para cumplir esta misión. Cabe entonces preguntarse ¿qué ofrece la escuela para aportar en la formación para la ciudadanía? Las respuestas abundan; sin embargo, en esta experiencia se optó por el enfoque de competencias ciudadanas y con la convicción de que este es un enfoque experiencial se generó la estrategia didáctica aquí documentada. Con el interés, además, de que sea replicada por muchas más instituciones, por más maestros y en otras regiones que se sumen al interés compartido de hacer de los escenarios escolares un laboratorio de convivencia y lograr, con el saber pedagógico, alentar transformaciones de fondo en los sistemas sociales que habitamos y que nos habitan.

\section{Referencias}

Ausbel, D., Novak, J. y Hanesian, H. (1976). Psicología educativa. Punto de vista cognoscitivo. México D.F.: Trillas. 
Barragán, F. y Arias, A. (2014). Dilemas morales para contextos rurales: Construcción y validación en básica secundaria de una institución educativa colombiana. Revista Electrónica Educare, 18(2), 95-116. Recuperado de http://www. revistas.una.ac.cr/index.php/EDUCARE/article/view/5835/5707 https://doi.org/10.15359/ ree.18-2.5

Bauman, Z. y Donskis, L. (2015). Ceguera moral. Barcelona: Paidós.

Bautista, G., Borges, F. y Forés, A. (2006). Didáctica universitaria en entornos virtuales de enseñanza-aprendizaje. Madrid: Narcea Editores.

Benavides, J. (2005). Entre la tecnología de la información y la pedagogía. Revista de Estudios Latinoamericanos, 16-17, 63-70. Pasto, Colombia: Universidad de Nariño.

Bermúdez, A. y Jaramillo, R. (2000). El análisis de dilemas morales: una estrategia pedagógica para el desarrollo de la autonomía moral. Bogotá: Secretaría Distrital de Educación, Corpoeducación.

Caballero, J., Romero, R., Barroso, J. y Román, P. (2007). Diseño y producción de TIC para la formación: nuevas tecnologías de la información y la comunicación. Barcelona: Universitat Oberta de Catalunya.

Camps, V. (2011). El gobierno de las emociones. Barcelona: Herder.

Chaux, E. (2012). Educación, convivencia y agresión escolar. Bogotá: Editorial Taurus, Santillana, Ediciones Uniandes. https://doi. org/10.7440/2012.62

Coll, C., Martin, T., Miras, M., Mauri, T., Onrubia, J., Solé, I. y Zabala, A. (2007). El constructivismo en el aula. México D.F.: Graó.

Corbetta, P. (2010). Metodología y técnicas de investigación social. Madrid: McGraw Hill.

Filloux, J. C. (2001). Campo pedagógico y psicoanálisis. Buenos Aires: Nueva Visión.
Gardner, H. (2005). Las cinco mentes del futuro. Barcelona: Paidós.

Gervilla, A. (2006). Didáctica básica de la educación infantil: conocer y comprender a los más pequeños. Madrid: Narcea Ediciones.

Gómez-Heras, J. (2004). Teoría de la moralidad. Introducción a la ética comparada. Madrid: Síntesis.

Gowin, D. (1981). Educating. Nueva York: Cornell University Press.

Hernández, C. y Guárate, A. (2017). Modelos didácticos para situaciones y contextos de aprendizaje. Madrid: Narcea.

Lind, G. (2005). El método Konstanz de dilemas morales. Recuperado de https://www.uni-konstanz.de/ag-moral/pdf/Lind-2005_1-GuiaDilemasMorales-03.pdf

Mantilla, L. y Chahín, I. (2010). Habilidades para la vida: manual para aprenderlas y enseñarlas. Bilbao: Edex.

Nussbaum, M. (2005). El cultivo de la humanidad. Una defensa clásica de la reforma en la educación liberal. Barcelona: Paidós.

Pereira, R. (2011). Adolescentes en el siglo XXI. Entre impotencia, resiliencia y poder. Madrid: Morata.

Restrepo, B. (2003). Aportes de la investigación-acción educativa a la hipótesis del maestro investigador: evidencias y obstáculos. Revista Educación y Educadores. Recuperado de http:// educacionyeducadores.unisabana.edu.co/index.php/eye/article/view/529/622

Rosas, R. (2008). Piaget, Vigotski y Maturana: constructivismo a tres voces. Buenos Aires: Aique.

Tonda, E. (2001). La didáctica de las ciencias sociales en la formación del profesorado de educación infantil. Alicante: Publicaciones de la Universidad de Alicante.

Zambrano, A. (2015). Aproximaciones a la pedagogía de Philippe Meirieu: derivaciones hacia la práctica. Buenos Aires: Brujas.

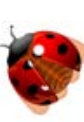

\section{(C) $(\otimes \odot \odot$}

Esta obra está bajo licencia Creative Commons Atribución-NoComercial-Compartirlgual 4.0 Internacional https://creativecommons.org/licenses/by-nc-sa/4.0/deed.es ISSN 1657-9089 • Vol 18, No 1 (enero-junio 2019). pp. 9-20 